\title{
Dementia and Alzheimer Disease: The Importance of Considering the Human, Social and Political Context in Research and Practice \\ P Cloos
}

\begin{abstract}
Objective: To suggest some avenues of research and priorities in the Caribbean in the domain of dementia and Alzheimer disease from a social science perspective.

Methods: To present and discuss, based on the current literature, the recommendations that were made by the participants of an international workshop on Alzheimer disease that was organized in 2013 during the annual conference of the Caribbean Public Health Association.

Results: Workshop participants identified the following priorities: to assess dementia prevalence in Caribbean countries; to study knowledge, attitudes and practices with regard to dementia; to engage people with signs of dementia to talk about their experiences; to study the extent of social isolation among and stigmatization toward older people; to measure the quality of the social environment; to quantify resources and training challenges among health professionals with regard to ageing and dementia; to study policies and mechanisms needed for providing community level care; to assess social support for caregivers and persons diagnosed with Alzheimer; and to study access to health care services and education about risk factors among older people.

Conclusion: This short communication suggests the need to focus on political, social and individual factors to better understand and respond to both the ageing of Caribbean societies and the concomitant raise of dementia prevalence.
\end{abstract}

Keywords: Alzheimer disease, dementia, humanity, medical anthropology, social determinants of health

From: Faculty of Arts and Science, University of Montreal, Montréal, Québec, Canada.

Correspondence: Professor P Cloos, Faculty of Arts and Sciences, 3150, rue Jean-Brillant, Université de Montréal, Montréal, Canada. Fax : +1514 343-2493, e-mail : patrick.cloos@umontreal.ca 


\section{INTRODUCTION}

It is estimated that by 2040 almost three-quarters of all people with dementia will be living in developing countries (1). Dementia is described as a set of symptoms associated with cognitive decline and language impairment that prevent people from carrying out daily activities. Alzheimer disease (AD) is often presented as the most frequent cause of progressive dementia in damaging brain cells with a prevalence that increases with older age (2). However, it is worth noting that dementia, including $\mathrm{AD}$, is not yet well understood and there is no known effective cure for Alzheimer (3), suggesting that early detection through biomarkers may be questionable (4). It has been noticed that the overall reduction of dementia incidence might occur in controlling vascular risk factors (diabetes, hypertension, smoking, physical inactivity) and guarantying access to education (5). However, these factors are in turn directly correlated with poverty and inequalities - both seen as social determinants of health (6) that have not received great attention in the AD domain (7).

In order to stimulate research on dementia, a 2-day workshop was organized in Barbados in the spring of 2013. The objectives were to identify research areas on Alzheimer's disease and related dementias among older people in the West Indies. This international workshop was entitled 'Canada-Caribbean Exploratory Meeting to Establish Partnerships on Alzeimer's Disease and related dementias'. It was organized in collaboration with the 57th Annual Caribbean Health Research Council and Caribbean Public Health Association's Scientific Conference. The participants of the workshop came from Canada and Caribbean countries (Barbados, Dominica, Trinidad and Tobago, and Jamaica). The attendance was mainly composed by medical and public professionals, and members of Alzheimer societies. Oral presentations from Canadian and 
Caribbean participants and working groups were organized to facilitate knowledge exchange about the topic and the identification of dementia-related regional needs to initiate research.

\section{Some research topics}

Research priorities were discussed and the need for prevalence studies was identified as there is a paucity of such data in the English-speaking Caribbean countries. In fact, to the best of our knowledge, only one study conducted in 2010 among 200 adults aged over 60 years old living in Kingston, Jamaica reported dementia rate of 5,3\% (8). It was based on a screening that used Mini Mental State Evaluation and clinical diagnosis referring to DSM IV criteria. Workshop participants also identified the need to study knowledge, attitudes and practices with regard to dementia. Medical knowledge can be limited among the population and care givers living in low socioeconomic circumstances (6) and this can impede health seeking behavior (9) and adequate care (10).

Regarding attitudes, participants raised concerns about stigmatization/exclusion of people diagnosed with Alzheimer disease (and consequent delay in consulting a health professional and delay of diagnosis). In relation to this matter, the need to engage people with signs of dementia to talk about their experiences to the general public, and the problem of social isolation of older people were also identified as a priority. Stigmatization along with social isolation and exclusion among older people in the Caribbean are concerns that were already raised by Cloos et al. (11). Research that focus on family support in the Caribbean was also seen as important by workshop participants.

On this matter, it has already been suggested that the quality of the social environment (social integration, networks and engagement) positively impact on people's cognitive function (12). Regarding research on health care services, workshop participants identified the following topics as priorities: to quantify resources and training challenges (e.g., lack of training among 
health care professionals, a situation seen as leading to their misunderstanding of behaviors associated with dementia and consequent inadequate health practices), and to study policies and mechanisms needed for providing community level care (assisted living facilities, nursing homes, e.g.).

The assessment of social support for caregivers and persons diagnosed with Alzheimer such as D-care facilities and the existence of respite possibilities for caregivers were seen as important. The identification of such topics were already identified by authors $(11,13)$. Furthermore access to health care services and education about vascular risk factors can be limited for people living in poor settings (6), a situation that can increase chronic diseases rates in the adult population and the risk of dementia later in life $(5,13)$.

The variety of topics and challenges that are associated with dementia show the need to focus on political and social factors to better understand and respond to both the ageing of Caribbean societies and the concomitant raise of dementia prevalence. Health promotion strategies should ideally guide all governmental policies since the whole environment has great impact on ageing health $(6,11)$. Furthermore, policies of age related problems should take into account population perceptions of aging and dementia. Finally, the human factor should be given priority in medical care. It is important to focus on lived experience and people's understanding of dementia and, when it comes to professional health practices, to relocate the older person in his/her specificity and unity. Finally, the diagnosis process should consider the environment including family dynamics and other interactions in order to interpret any signs of modifications in ageing (14). 


\section{ACKNOWLEDGMENTS}

Thank you to The Canadian Institute for Health Research for funding the workshop on Alzheimer disease in Barbados. Thank you to all the participants of the workshop. And thank you to Christiana Abraham for her attentive reading and comments.

\section{AUTHORS' NOTE}

Cloos organized the international workshop on Alzheimer disease in Barbados and conceived paper. 


\section{REFERENCES}

1. The Lancet Neurology. Time to confront the global dementia crisis. Lancet Neurol 2008; 7: 761. DOI: http://dx.doi.org/10.1016/S1474-4422(08)70175-3.

2. Alzheimer's Society. About dementia [Internet]. London: Alzheimer's Society; 2016 [cited October 2016]. Available from: https://www.alzheimers.org.uk

3. Fujii Y. Two Cases of Severe Dementia Showing Dramatic Improvement after Denture Placement. Advances in Alzheimer's Disease 2016, 5: 46-52.

4. Pimplikar SW. Alzheimer's Isn't Up to the Tests (Opinion). New York Times. 2010 July 19. [cited October 2016]. Available from: http://www.nytimes.com/2010/07/20/opinion/20pimplikar.html?_r=0

5. Norton S, Matthews FE, Barnes DE, Yaffe K, Brayne C. Potential for primary prevention of Alzheimer's disease: an analysis of population-based data. Lancet Neurol 2014; 13: 78894. Available from: www.thelancet.com/neurology

6. Blas E, Sivasankara KA (ed). Equity, social determinants and public health programmes. Geneva: World Health Organization; 2010. Available from: http://apps.who.int/iris/bitstream/10665/44289/1/9789241563970_eng.pdf

7. Lock M. The Alzheimer Conundrum. Entanglements of Dementia and Aging. New Jersey: Princeton University Press; 2013.

8. Neita SM, Abel WD, Eldemire-Shearer D, James K, Gibson RC. The prevalence and associated demographic factors of dementia from a cross-sectional community survey in Kingston, Jamaica. Int J Geriatr Psychiatry 2014, 29:103-5. 
9. Garvey G, Simmonds D, Clements V, O’Rourke P, Sullivan, K., Gorman D, et al. Making Sense of Dementia: Understanding amongst Indigenous Australians. Int J of Ger Psy 2011; 26: $649-56$.

10. Adamson J. Awareness and Understanding of Dementia in African/Caribbean and South Asian Families. Health \& Social Care in the Community 2001; 9: 391-6.

11. Cloos P, Alvarado BE, Zunzunegui MV, Eldemire-Shearer D, Simeon DT. Active Ageing: A qualitative study in six Caribbean countries. Ageing \& Society 2010; 30: 79-101.

12. Zunzunegui MV, Alvarado BE, Del Ser T, Otero A. Social Networks, Social Integration, and Social Engagement Determine Cognitive Decline in Community-Dwelling Spanish Older Adults. J of Gerontology: Social Sciences 2003; 58B: S93-S100.

13. Baboolal N, Davis G, McRae A. Trinidad and Tobago: A decade of dementia research. Dement. neuropsychol 2014: 8: 330-8.

14. Cloos P. Would there be a pathological way to ageing? The necessity to question 'Alzheimer disease'. Medicine and Anthropology Theory (In Press). 